\title{
Growth of seagrass Halophila ovalis at dugong trails compared to existing within-patch variation in a Thailand intertidal flat
}

\author{
Masahiro Nakaoka*, Keiko Aioi \\ Ocean Research Institute, University of Tokyo, Minamidai 1-15-1, Nakano, Tokyo 164-8639, Japan
}

\begin{abstract}
We studied small-scale variation in morphology and growth rate of the seagrass Halophila ovalis in an intertidal flat of Thailand coast where the seagrass bed is subjected to grazing by dugongs. Our objectives were to examine whether morphology and growth rate differ between rhizomes in different positions within a patch (center, edge and dugong trails), and to test whether $H$. ovalis shows plastic growth response to disturbance by dugong feeding. Seagrass biomass and leaf density were 3 to 4 times greater at the patch center than the patch edge and the dugong trails. In contrast, branching rate and internode length of rhizomes were significantly greater at the patch edge and dugong trails than at the patch center. The results of marking experiments of $H$. ovalis revealed that net production, leaf production and rhizome elongation rates were 2 to 3 times greater at the patch edge than at the center. Growth and production rates at the edge of the dugong trails and artificial trails mimicking dugong trails were not significantly higher than at the patch center. Nevertheless, significant differences in some morphological parameters such as branching frequency and internode length between the dugong trails and the patch center suggest that morphological changes in $H$. ovalis can be induced over short time scales. Recovery of $H$. ovalis after disturbance by dugong herbivory was estimated to be quite rapid $(<20 \mathrm{~d})$. High growth rates of $H$. ovalis were probably responsible for its persistence under grazing by dugongs.
\end{abstract}

KEY WORDS: Halophila ovalis - Seagrass - Within-patch variation - Growth P Production - Dugong herbivory $\cdot$ Morphological plasticity Thailand S Small-scale heterogeneity

\section{INTRODUCTION}

Seagrasses are clonal plants that sometimes form dense beds or patches. In terrestrial clonal plants, it is known that growth rate and morphology are not always uniform among different positions within a patch or even a single genet (Keddy 1981, 1982, Adachi et al. 1996, Steuer et al. 1996, Hutchings \& Wijesinghe 1997). In general, better growth of modules is expected at peripheral rather than at central positions of a patch, when modules are released from crowding effects or competition at the periphery (ecological factors), or when there are aging effects on growth or morphology at the center (autogenic factors).

•E-mail: nakaoka@ori.u-tokyo.ac.jp
This general prediction can also apply to clonal seagrasses, although only a few studies have examined small-scale variation in growth or morphology within a patch or a single genet (Zieman 1972, Brouns 1987a, Duarte \& Sand-Jensen 1990, Marbà \& Duarte 1995 , Turner et al. 1996, Vermat et al. 1997).

The seagrass species belonging to the genus Halophila occur on intertidal and subtidal soft bottoms of tropical and subtropical coasts. Among various tropical seagrass species, Halophila ovalis is known to be preferred by dugongs Dugong dugon (Preen 1995). Dugongs leave unvegetated feeding trails in seagrass patches (Heinsohn et al. 1977), but sometimes their intensive feeding activity changes dense unfragmented seagrass beds into bare sand flats (Preen 1995). However, $H$. ovalis is the fastest growing seagrass species in tropical seagrass beds (Vermaat et al. 
1995), and this may play an important role in maintaining population size in the face of extensive herbivory (Preen 1995). For example, Supanwanid (1996) observed in a Thailand intertidal flat that $H$. ovalis biomass in artificial trails mimicking dugong trails recovered to original levels within $2 \mathrm{mo}$. It is possible that such rapid recovery is dependent on a plastic response in growth because shoots and rhizomes in central positions of a patch can suddenly become peripheral when subjected to the disturbance caused by dugong herbivory.

The main objectives of the present study are (1) to examine whether morphology and growth rate of Halophila ovalis differ between different positions within patches, i.e. the patch center and patch edge, and (2) to test whether $H$. ovalis shows plastic growth response to disturbance by dugong herbivory. We conducted a quantitative sampling and a marking experiment at several different positions in $H$. ovalis patches, as well as at edges of dugong feeding trails and artificially made trails resembling dugong feeding trails.

\section{MATERIALS AND METHODS}

Study site. We carried out the fieldwork during March 11 through March 24, 1998, in an intertidal flat at Koh Bae $\mathrm{Na}$, located at Haad Chao Mai Marine National Park, on the southwestern coast of Thailand (Fig. 1). The tidal range during the research period

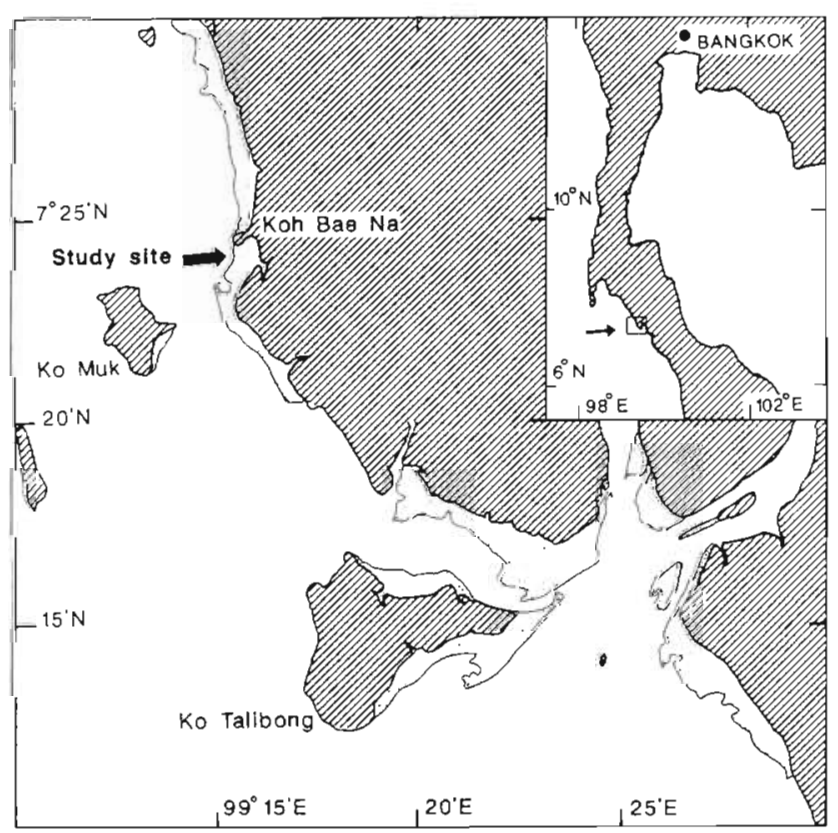

Fig. 1. Study site at Koh Bae Na, Haad Chao Mai National Park, in Thailand varied between $0.7 \mathrm{~m}$ (neap tide) and $2.8 \mathrm{~m}$ (spring tide). At spring ebb, the intertidal flat extends about $400 \mathrm{~m}$ from the shoreline. A seagrass bed of ca 3 ha area covers the lower half of the intertidal flat. The most dominant seagrass species is Halophila ovalis, followed by Cymodocea rotundata, C. serrulata and Enhalus acoroides. Each seagrass species forms monospecific stands of patches of various sizes $\left(<1\right.$ to $\left.100 \mathrm{~m}^{2}\right)$ and shapes. Coverage of each seagrass species measured at a $10000 \mathrm{~m}^{2}$ quadrat was $61 \% \mathrm{H}$. ovalis, $10 \%$ C. rotundata, $1 \%$ C. serrulata, and $<1 \%$ E. acoroides, while $28 \%$ was unvegetated mudflat (H. Mukai unpubl. data).

Six individuals of dugongs were observed around the study site (intertidal and subtidal seagrass beds between Ko Muk and Koh Bae Na; Fig. 1) by an aerial survey conducted on April 9, 1997 (Adulyanukosol et al. 1997). During our research period, 1 dugong (probably the same individual) was observed in the tidal flat for $7 \mathrm{~d}$ at high tide in the daytime, leaving 6 to 29 (15 on average) new feeding trails per day in the 1 ha quadrat (H. Mukai unpubl. data). The average size of feeding trails is $200 \mathrm{~cm}$ in length, $15 \mathrm{~cm}$ in width and $3 \mathrm{~cm}$ in depth. Dugongs feed more efficiently on the aboveground part of Halophila ovalis than the belowground, leaving in the feeding trails only $6.1 \%$ $( \pm 1.3 \mathrm{SD})$ of initial biomass of the former, and $39 \%$ $( \pm 13.2 \mathrm{SD})$ of the latter (T. Suzuki unpubl. data).

Within-patch variation in abundance and morphology. We compared abundance, biomass and vegetative morphology of Halophila ovalis at 3 different positions within the patches ${ }_{i}(1)$ in the center of the $H$. ovalis patches ('patch center'), (2) at the edge of the patches adjoining the unvegetated mud flat ('patch edge'), and (3) along the edge of the dugong feeding trails ('dugong trails'). The patch center is defined as the area $>3 \mathrm{~m}$ inside the patch margin, and the patch edge within $20 \mathrm{~cm}$ from the margin. We collected $H$. ovalis at each position from within a $20 \times 20 \mathrm{~cm}$ quadrat (4 samples from the patch center and the patch edge, and 3 from the dugong trails) by digging down to a depth of $10 \mathrm{~cm}$ using a hand shovel, and removing the sediment using sieves of $1 \mathrm{~mm}$ mesh opening. We counted the numbers of leaves and rhizome apices in each sample. We then measured the length and width of leaf blade, the distances between successive nodes of rhizomes (individual internode length), and the branching frequency (expressed by the ratio of the number of nodes with a branch axis to the total number of nodes) of 20 haphazardly selected ramets from each sample. Individual leaf area was approximated as an area of ellipse with leaf length as the longer axis and leaf width as the shorter axis. Finally, we separated aboveground parts (leaves and petioles) and belowground parts (rhizomes and roots) 
of all the collected seagrasses, dried them in an oven at $60^{\circ} \mathrm{C}$ for $48 \mathrm{~h}$, and measured them on an electronic balance (to the nearest $0.1 \mathrm{mg}$ ) to obtain the dry weight of each part. The root:shoot ratio was expressed as the weight of belowground parts divided by that of aboveground.

Within-patch variation in growth rate. We measured the growth rate of Halophila ovalis at 4 different positions in patches; (1) at patch centers, (2) at patch edges, (3) at the edge of the dugong trail, and (4) at the edge of artificial trails. Two artificial trails to resemble dugong feeding trails (each $2 \mathrm{~m}$ long and $15 \mathrm{~cm}$ wide) were made in the center of a patch by digging up the sediment in the seagrass bed to a depth of $10 \mathrm{~cm}$ with a hand shovel and then by replacing the sediment once the $H$. ovalis had been removed manually.

We marked rhizomes of Halophila ovalis by tagging plastic-coated steel wire $(3 \mathrm{~mm}$ in width and $0.5 \mathrm{~mm}$ in thickness) around the second node from the growing apex. Marking was carried out at low tide on March 12 to 15,1998 , when the $H$. ovalis bed was exposed or shallower than $10 \mathrm{~cm}$ deep. Some disturbance to the seagrass may have been caused when we dug the sediment by hand at a depth of about 1 to $3 \mathrm{~cm}$ to look for growing apices. However, the impact appeared to be minor because the marked rhizomes were observed to retain their position underground after the arrival of the first high tide. Ten seagrass rhizomes were marked at each of the 3 sites of patch centers, 3 at patch edges, 2 at dugong trails and 2 at artificial trails. The marked rhizomes were recovered on March 22, 1998 ( 7 to $10 \mathrm{~d}$ later) at the lowest tide. During the experimental period, 40 to $80 \%$ of plants with tags were washed away at each site. Nevertheless, we retrieved 6 to 12 marked rhizomes per position which is sufficient to perform statistical analyses (see below). The number of new leaves, length and the branching frequency of extended rhizomes, and dry weight of newly produced aboveground and belowground parts were measured as described above.

Statistical analyses. Some of the parameters representing seagrass abundance, morphology and growth were expressed on a sample basis (per unit area), and other parameters on a ramet basis (per ramet within each sample). We tested within-patch (among-position; center, edge and trail-edge) variation in the former parameters using 1-way ANOVA, and amongand within-position variation in the latter using 1-way nested ANOVA. The data were log transformed before the analyses when significant differences in variance were detected among data (tested with Cochran's test). When significant variation among positions was detected by ANOVA, post-hoc comparisons were carried out with the Tukey-Kramer method (at a significance level of $\alpha=0.05$ ). For the branching fre- quency of newly produced rhizomes in the marking experiment, among-position variation was tested with non-parametric Kruskal-Wallis test instead of ANOVA because the data did not fulfill the assumption of normality. Post-hoc comparisons were made with Mann-Whitney $U$-test after adjusting the probability of overall Type I error $(\alpha=0.05)$ by the Dunn-Sidák method.

\section{RESULTS}

\section{Within-patch variation in abundance and morphology}

Total biomass, aboveground and belowground biomass, densities of leaves and rhizome apices were about 3 to 4 times greater at patch centers than at patch edges or dugong trails (Fig. 2). One-way ANOVA revealed significant among-position variation in these parameters $(p=0.010$ for total biomass; $p=$
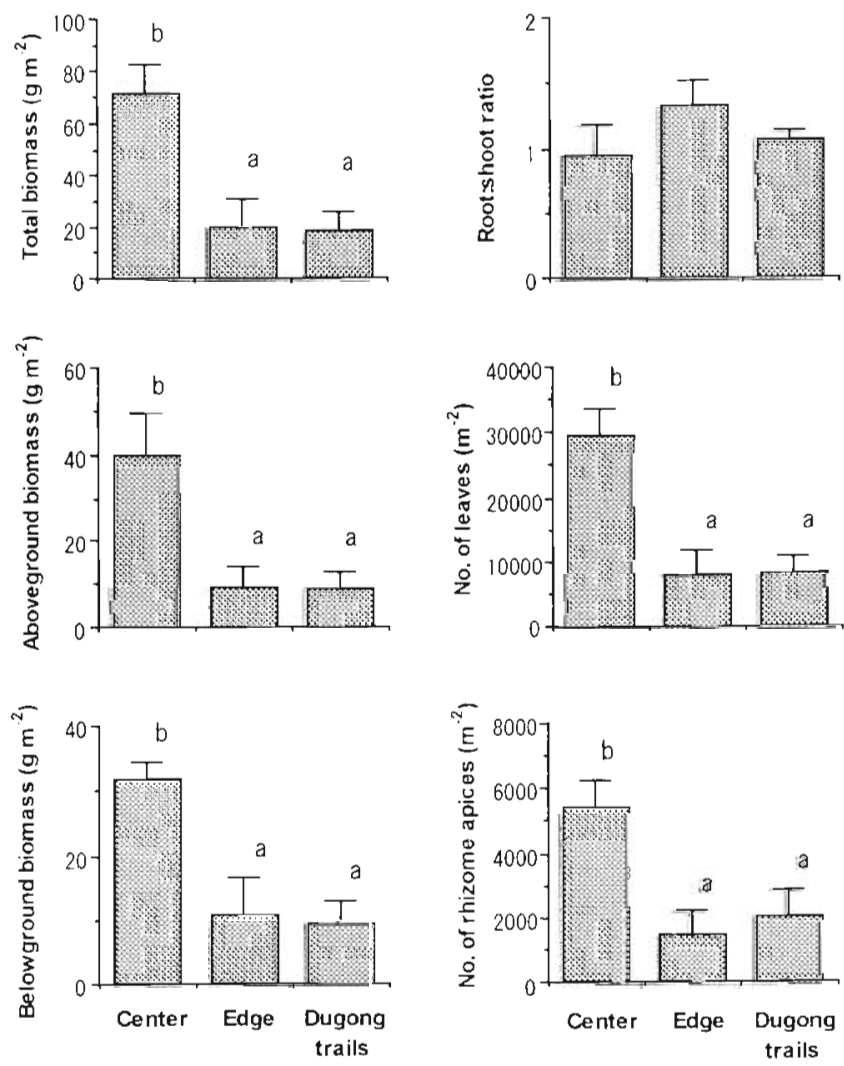

Fig. 2. Halophila ovalis. Variation in parameters representing abundance among 3 position types within patches. Bars are the means of 4 (center and edge) and 3 (dugong trails) replicates and error bars are standard errors of the mean. Different letters denote pairs of positions where significant amongposition variation was detected by the post-hoc comparisons 

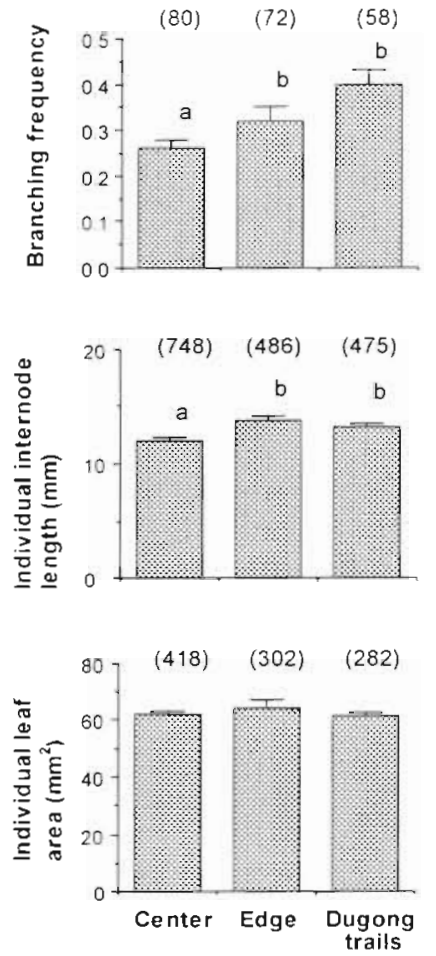

Fig. 3. Halophila ovalis. Variation in morphology among positions within patches. Bars indicate the means, and error bars are standard errors of the mean. The numbers in parentheses indicate sample sizes. Different letters denote pairs of positions where significant among-position variation was detected by the post-hoc comparisons

0.024 for aboveground biomass; $p=0.011$ for belowground biomass; $\mathrm{p}=0.005$ for density of leaves; and $\mathrm{p}=$ 0.016 for density of rhizome apices). Post-hoc comparison showed that parameters at patch centers were significantly higher than at patch edges and at dugong trails, whereas the differences between the latter two were not significant (Fig. 2). In contrast, branching frequency and individual internode length of rhizomes were significantly greater at patch edge and dugong trails than at patch center although significant withinposition variation was also detected for these parameters (Fig. $3 ; 1$-way nested ANOVA; $p=0.002$ for among-position and $p=0.001$ for within-position variation of branching frequency; and $p<0.001$ for both among-position and within-position variation of individual internode length). Among-position variation was not obvious for root:shoot ratio and individual leaf area (Figs. 2 \& 3). No significant among-position variation was found for either parameters, although individual leaf area varied significantly among samples within each position (1-way ANOVA: $p=0.397$ for root:shoot ratio; 1 -way nested ANOVA: $p=0.884$ for among-position and $p<0.001$ for within-position variation of individual leaf area).

\section{Within-patch variation in growth rate}

A total of 35 tagged rhizomes of Halophila ovalis was collected at 4 patch positions. Net production, leaf production and rhizome elongation rates differed significantly among patch positions: they were 2 to 3 times greater at patch edges than at patch centers, and those at the edge of dugong trails and artificial trails were not significantly different from the rates observed at the centers (Fig. 4, Table 1). These parameters varied significantly not only among positions, but also among different ramets of each position (Table 1).

Tagged rhizomes produced 1 to 5 branches at the patch edges and the 2 types of trails, but no branches were produced at the patch centers. The branching frequency of newly produced rhizomes varied significantly among positions (Kruskal-Wallis test; $p<0.001$ ), and it was higher at patch edges and the dugong trails than at patch centers (Fig. 4) Individual internode
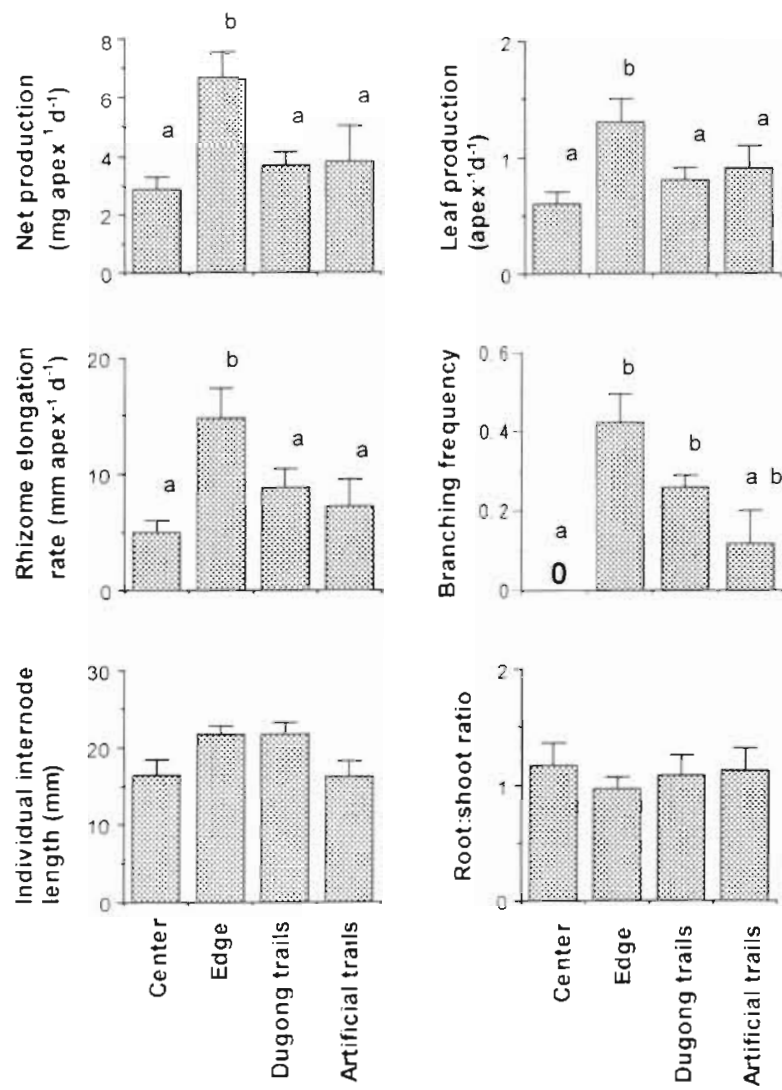

Fig. 4. Halophila ovalis. Variation in growth, production and morphology among positions within patches of newly produced modules in the marking experiment. Bars are the means of 12 (center), 10 (edge), 7 (dugong trails) and 6 (artificial trails) replicates and error bars are standard errors of the mean. Different letters denote pairs of positions where significant among-position variation was detected by the post-hoc comparisons. Branching frequency was 0 because no branches were produced at the patch centers 
Table 1 Halophila ovalis. Result of 1 -way nested ANOVA testing within-patch variation in the growth rates and morphology of marked rhizomes

\begin{tabular}{|c|c|c|c|c|}
\hline Factor & df & SS & $F$ & $\mathrm{p}$ \\
\hline \multicolumn{5}{|l|}{ Net production } \\
\hline Position & 3 & 52.92 & 8.101 & 0.001 \\
\hline Sample (position) & 6 & 93.88 & 7.186 & $<0.001$ \\
\hline Residual & 25 & 54.43 & & \\
\hline \multicolumn{5}{|l|}{ Leaf production } \\
\hline Position & 3 & 2.307 & 8.849 & $<0.001$ \\
\hline Sample (position) & 6 & 2.124 & 4.074 & 0.006 \\
\hline Residual & 25 & 2.173 & & \\
\hline \multicolumn{5}{|c|}{ Rhizome elongation rate } \\
\hline Position & 3 & 364.5 & 6.775 & 0.002 \\
\hline Sample (position) & 6 & 513.1 & 4.769 & 0.002 \\
\hline Residual & 25 & 448.3 & & \\
\hline \multicolumn{5}{|c|}{ Individual internode length } \\
\hline Position & 3 & 173.7 & 2.796 & 0.061 \\
\hline Sample (position) & 6 & 292.6 & 2.356 & 0.061 \\
\hline Residual & 25 & 517.6 & & \\
\hline \multicolumn{5}{|l|}{ Root:shoot ratio } \\
\hline Position & 3 & 0.456 & 0.778 & 0.517 \\
\hline Sample (position) & 6 & 3.678 & 3.138 & 0.020 \\
\hline Residual & 25 & 4.884 & & \\
\hline
\end{tabular}

length and root:shoot ratio did not vary among any of the habitat positions, although significant within-position (among-ramet) variation was detected for the root:shoot ratio (Table 1 ).

\section{DISCUSSION}

We found in the present study that the morphology and growth rate of Halophila ovalis differ significantly among positions within a seagrass patch. The observed pattern in within-patch variation in growth and production (better growth and greater production at the patch edges than at the centers) agrees with the review by Vermaat et al. (1997), which confirms that growth rates are faster at patch edges than inside patches in 4 out of 5 seagrass species (Cymodocea nodosa, C. serrulata, $H$. ovalis and Syringodium isoetifolium, but not in Zostera noltii).

The better growth and greater production at the patch edges can be caused by at least 2 (not fully exclusively) alternative factors; (1) release at patch edges from negative density effects or crowding effects (Antonovics \& Levin 1980), and (2) aging effects of old ramets near patch centers (Masuzawa \& Suzuki 1991). In the present Halophila ovalis population, the first factor is likely to be responsible because biomass and leaf density were more than 3-fold greater at the patch center. Mean LAI (leaf area index; the ratio of total leaf area to bottom area) was 1.82 at the patch centers, while it was 0.50 both at patch edges and dugong trails (calculated from data on individual leaf area in Fig. 3 and leaf density in Fig. 2). It is therefore likely that seagrasses may undergo competition for light at patch centers but not at patch edges. Furthermore, biomass at the patch center estimated in this study is among one of the highest estimates for $H$. ovalis when compared with other available data (Table 2). This might also suggest that crowding effects could play a role in within-patch variation. The second factor, on the other hand, seems unlikely because we found a large number of newly growing apices even at patch centers (Fig. 2).

Comparison of growth and morphology between the patch center and the dugong trails revealed the plastic change in some morphological parameters, such as rhizome branching frequency and individual internode

Table 2. Halophila ovalis. Comparisons of biomass, growth and production at different localities

\begin{tabular}{|c|c|c|c|c|}
\hline Locality & $\begin{array}{c}\text { Biomass } \\
\text { (g dry wt } \mathrm{m}^{-2} \text { ) }\end{array}$ & $\begin{array}{c}\text { Rhizome } \\
\text { elongation rate } \\
\left(\mathrm{mm} \operatorname{apex}^{-1} \mathrm{~d}^{-1}\right)\end{array}$ & $\begin{array}{c}\text { Production } \\
\text { (g dry wt } \mathrm{m}^{-2} \mathrm{~d}^{-1} \text { ) }\end{array}$ & Source \\
\hline \multicolumn{5}{|l|}{ Monospecific bed } \\
\hline Arabian Sea coast of Oman & $0.5-11.4$ & - & - & Jupp et al. (1996) \\
\hline NE coast of Saudi Arabia & $12-39$ & - & - & Kenworthy et al. (1993) \\
\hline Ashtamudi estuary, SW India & $\leq 48$ & - & - & Nair et al. (1983) \\
\hline Swan/Canning Estuary, SW Australia & $\leq 120$ & - & $\leq 40$ & Hillman et al. (1995) \\
\hline Moreton Bay, Australia & 75 & - & - & Preen (1995) \\
\hline SW coast of Thailand & 30 & - & - & Supanwanid (1996) \\
\hline SW coast of Thailand & 72 & $5.0-14.8$ & $7.5-15.6$ & Present study \\
\hline \multicolumn{5}{|l|}{ Mixed bed } \\
\hline Sinài, Northern Red Sea & $16-20$ & - & - & Lipkin (1979) \\
\hline Bolinao reef flat, Phillipines & 0.2 & 3.9 & 0.04 & Vermaat et al. (1995) \\
\hline Bootless Inlet, Papua New Guinea & 1.0 & 5.5 & $<0.02$ & Brouns $(1987 a, b)$ \\
\hline Palau, Micronesia & 2 & - & - & Ogden \& Odgen (1982) \\
\hline
\end{tabular}


length (Figs. 3 \& 4). Such morphological changes are considered to be adaptive when open spaces appear due to sudden disturbance, because seagrass clones can invade and occupy open spaces quickly if they can extend more branches or increase the intervals of each node. A similar type of plastic change in seagrass morphology has been reported for other seagrass species in response to physical disturbance such as sedimentation and dune migration (Marbà \& Duarte 1995, Duarte et al. 1997). The present study suggested that such morphological changes in seagrasses can also occur in response to biological disturbance by herbivorous animals, and that they can be induced in quite short time scale (within a week or $10 \mathrm{~d}$ ).

Unlike the morphological parameters described above, we could not detect significant differences between the patch centers and the trail edges for parameters representing growth and production (Fig. 4, Table 1). We had expected that growth and production at the trails become similar to those at patch edges if the local release from clouding effects or competition were most responsible for producing within-patch variation in these parameters. Failure to detect significant differences may imply that the seagrass cannot attain higher growth rate or greater production on the short time scale. It is likely that the seagrass apices at the edges of dugong trails are damaged due to dugong foraging (e.g. either by herbivory or by disturbance of sediment during the feeding), which may be responsible for a delay in growth response.

Based on the data collected in the present study, it is possible to make rough estimates of the recovery rates of Halophila ovalis after disturbance by dugong feeding. Assuming that rhizomes at the margin of dugong trails can grow across dugong trails (width of 10 to $33 \mathrm{~cm} ; \mathrm{H}$. Mukai unpubl. data) at the elongation rate of $8.8 \mathrm{~mm}$ apex ${ }^{-1} \mathrm{~d}^{-1}$ (Fig. 4), it takes only 6 to $19 \mathrm{~d}$ for rhizome apices to reach the center of the trails from both sides. Furthermore, based on daily net production per unit area at the dugong trails $\left(7.5 \mathrm{~g}\right.$ dry weight $\mathrm{m}^{-2} \mathrm{~d}^{-1}$; see below for the method of calculation), it is estimated to take less than $10 \mathrm{~d}$ to reach the biomass at the center ( $72 \mathrm{~g} \mathrm{dry}$ weight $\mathrm{m}^{-2}$; Fig. 2) starting from an unvegetated state. In the present study site, Supanwanid (1996) demonstrated in a manipulative experiment that biomass of $H$. ovalis recovered in 2 mo to the initial level after its removal in an artificial trail resembling dugong feeding trails. Our estimates on the recovery rate of $H$. ovalis are much higher than the estimates of Supanwanid. In the present study, we have assumed constant growth rates and no mortality. Seagrass growth rates may decrease and shoot/leaf mortality rates may increase at the dugong trails as seagrass density and biomass increase during the course of recovery. In addition, we do not know whether all the rhizome apices in our sampling quadrates $(20 \times 20 \mathrm{~cm})$ produced new rhizomes and leaves towards the unvegetated feeding trails. Finally, $H$. ovalis may exhibit large seasonal and annual variation in growth and productivity, as revealed in other localities (Hillman et al. 1995). Such factors may have contributed to a discrepancy between our estimates and those of Supanwanid (1996). Longer-term studies on shoot demography and patch dynamics are necessary to gain more precise estimates on the recovery rates of $H$. ovalis in response to dugong feeding.

Daily production per unit area is estimated to be $7.5 \mathrm{~g}$ dry weight $\mathrm{m}^{-2} \mathrm{~d}^{-1}$ at the dugong trails, $9.9 \mathrm{~g}$ dry weight $\mathrm{m}^{-2} \mathrm{~d}^{-1}$ at the patch edge, and $15.6 \mathrm{~g}$ dry weight $\mathrm{m}^{-2} \mathrm{~d}^{-1}$ at the patch center (calculated from the data on the density of rhizome apices in Fig. 2 and the daily production rates per apex in Fig. 4). The growth and production rates estimated in the present study are mainly higher than those obtained for Halophila ovalis at other localities (Table 2). At our study site, daily consumption rate on $H$. ovalis by a dugong (visited by 1 individual during the research period) is estimated to be ca $0.06 \mathrm{~g}$ dry weight $\mathrm{m}^{-2} \mathrm{~d}^{-1}$ (H. Mukai unpubl. data). Therefore, the loss of seagrass by dugong feeding can be fully compensated by the high productivity of $H$. ovalis. Preen (1995) demonstrated that high productivity and rapid recovery rate of $H$. ovalis following intense grazing by dugongs are responsible for the persistence of this pioneer species among late successional species such as Zostera capricorni in Australia. A similar mechanism may explain the consistent persistence of $H$. ovalis in the present study site.

In conclusion, the present study demonstrated that growth and morphology of seagrasses can vary greatly even within a single patch, although it failed to detect plastic changes in growth and production in response to dugong herbivory. The fact that seagrass growth and production can vary greatly at small scales has large implications on studies of seagrass ecosystems at larger scale, because estimates of large-scale processes neglecting small-scale variation may lead to large biases in comparisons made over wider geographical scales (Thrush et al. 1997). The integrated approach to studying seagrass dynamics concurrently at several different scales (e.g. rhizome demography, patch dynamics and landscape patterns) is promising to understand effects of different scales on the dynamics of seagrass ecosystems (Turner et al. 1996).

Acknowledgements. We wish to thank K. Lewmanomont, C. Supanwanid, and staff in the Marine National Park Supporting Center, Thailand, for their invaluable support in various aspects of this research project. T Toyohara helped us in the field work, T. Arai, Y. Hashiguchi, N. Kawazoe and Y. Okuzaki helped us in the laboratory measurements and S. L. Williams provided valuable discussions, which were helpful for plan- 
ning the present study. J. Kuo, H. Mukai and 4 anonymous reviewers provided many useful comments on the manuscript. This research was supported by a Grant-in-Aid for the International Scientific Research Program (No. 09041147) from the Ministry of Education, Science, Culture and Sports, Japan.

\section{LITERATURE CITED}

Adachi N, Terashima I, Takahashi M (1996) Central die-back of monoclonal stands of Reynoutria japonica in an early stage of primary succession on Mount Fuji. Ann Bot (Lond) $77: 477-486$

Adulyanukosol K, Chantrapornsyl S, Poovachiranon S (1997) An aerial survey of dugong (Dugong dugon) in Andaman Coast, Thailand. Thai Fish Gaz 50:359-374

Antonovics J, Levin DA (1980) The ecological and genetic consequences of density-dependent regulation in plants. Annu Rev Ecol Syst 11:411-452

Brouns JJWM (1987a) Growth patterns in some Indo-WestPacific seagrasses. Aquat Bot 28:39-61

Brouns JJWM (1987b) Quantitative and dynamic aspects of a mixed seagrass meadow in Papua New Guinea. Aquat Bot 29:33-47

Duarte CM, Sand-Jensen K (1990) Seagrass colonization: biomass development and shoot demography in Cymodocea nodosa patches. Mar Ecol Prog Ser 67:97-103

Duarte CM, Terrados J, Agawin NSR, Fortes MD, Bach S, Kenworthy WJ (1997) Response of a mixed Philippine seagrass meadow to experimental burial. Mar Ecol Prog Ser $147: 285-294$

Heinsohn GE, Wake J, Marsh H, Spain AV (1977) The dugong (Dugong dugon (Muller)) in the seagrass system. Aquaculture 12:235-248

Hillman K, McComb AJ, Walker DI (1995) The distribution, biomass and primary production of the seagrass Halophila ovalis in the Swan/Canning Estuary, Western Australia. Aquat Bot 51:1-54

Hutchings MJ, Wijesinghe DK (1997) Patchy habitats, division of labour and growth dividends in clonal plants. Trends Ecol Evol 12:390-394

Jupp BP, Durako MJ, Kenworthy WJ, Thayer GW, Schillak L (1996) Distribution, abundance, and species composition of seagrasses at several sites in Oman. Aquat Bot 53:199-213

Keddy PA (1981) Experimental demography of the sand-dune annual, Cakile edentula, growing along an environmental gradient in Nova Scotia. J Ecol 69:615-630

Keddy PA (1982) Population ecology on an environmental gradient: Cakile edentula on a sand dune. Oecologia 52: 348-355

Kenworthy WJ, Durako MJ, Fatemy SMR, Valavi H, Thayer GW (1993) Ecology of seagrasses in northeastern Saudi Arabia one year after the Gulf War oil spill. Mar Pollut Bull $27: 213-222$

Editorial responsibility: Otto Kinne (Editor), Oldendorf/Luhe, Germany
Lipkin Y (1979) Quantitative aspects of seagrass communities, particularly of those dominated by Halophila stipulacea, in Sinai (Northern Red Sea). Aquat Bot 7:119-128

Marbà N, Duarte CM (1995) Coupling of seagrass (Cymodocea nodosa) patch dynamics to subaqueous dune migration. J Ecol 83:381-389

Masuzawa T, Suzuki J (1991) Structure and succession of alpine perennial community (Polygonum cuspidatum) on Mt. Fuji. Proc NIPR Symp Polar Biol 4:155-160

Nair NB, Arunachalam M, Azis PKA, Dharmaraj K, Kumar KK (1983) Ecology of Indian estuaries: Part II. Ecology of seagrass bed of Halophila ovalis (Hook) in the Ashtamudi estuary, SW coast of India. Indian J Mar Sci 12:151-153

Ogden JC, Ogden NB (1982) A preliminary study of two representative seagrass communities in Palau, West Caroline Islands (Micronesia). Aquat Bot 12:229-244

Preen A (1995) Impacts of dugong foraging on seagrass habitats: observational and experimental evidence for cultivation grazing. Mar Ecol Prog Ser 124:201-213

Steuer JF, de Kroon H, During HJ (1996) Exploitation of environmental heterogeneity by spatial division of labour in a clonal plant. Funct Ecol 10:328-334

Supanwanid C (1996) Recovery of the seagrass Halophila ovalis after grazing by dugong. In: Kuo J, Phillips RC, Walker DI, Kirkman H (eds) Seagrass biology: Proc Int workshop, Rottenest Island, Western Australia. Faculty of Science, The University of Western Australia, Nedlands, p 315-318

Thrush SF, Dayton PK, Hines AH, Grant J, Legendre P, McArdle BH, Pridmore RD, Schneider DC, Turner SJ, Whitlatch RB, Cummings VJ, Hewitt JE, Wilkinson MR (1997) The sandflat habitat: scaling from experiments to conclusions. J Exp Mar Biol Ecol 216:1-9

Turner SJ, Thrush SF, Wilkinson MR, Hewitt JE, Cummings VJ, Schwarz AM, Morrisey DJ, Hawes I (1996) Patch dynamics of the seagrass Zostera novazelandica (?) at three sites in New Zealand. In: Kuo J, Walker DI, Kirkman $\mathrm{H}$ (eds) Seagrass biology: scientific discussion from an international workshop, Rottenest Island, Western Australia. Faculty of Science. The University of Western Australia, Nedlands, p 21-31

Vermaat JE, Agawin NSR, Duarte CM, Fortes MD, Marbà N, Uri JS (1995) Meadow maintenance, growth and productivity of a mixed Philippine seagrass bed. Mar Ecol Prog Ser 124:215-225

Vermaat JE, Agawin NSR, Fortes MD, Uni JS, Duarte CM, Marbà N, Enriquez S, van Vierssen W (1997) The capacity of seagrasses to survive increased turbidity and siltation: the significance of growth form and light use. Ambio 26: 499-504

Zieman JC (1972) Origin of circular beds of Thalassia (Spermatophyta: hydrocharitaceae) in south Biscayne Bay, Florida, and their relationship to mangrove hammocks. Bull Mar Sci 22:559-574

Submitted: August 25, 1998; Accepted: March 16, 1999 Proofs received from author(s): July 2, 1999 